\title{
A Simplified Supercritical Fast Reactor with Thorium Fuel
}

\author{
Peng Zhang, ${ }^{1,2}$ Kan Wang, ${ }^{1}$ and Ganglin Yu ${ }^{1}$ \\ ${ }^{1}$ Department of Engineering Physics, Tsinghua University, Beijing 100084, China \\ ${ }^{2}$ School of Power and Mechanical Engineering, Wuhan University, Wuhan 430072, China
}

Correspondence should be addressed to Peng Zhang; zhangpeng03@gmail.com

Received 6 December 2013; Revised 21 January 2014; Accepted 22 January 2014; Published 10 March 2014

Academic Editor: Jiejin Cai

Copyright ( 2014 Peng Zhang et al. This is an open access article distributed under the Creative Commons Attribution License, which permits unrestricted use, distribution, and reproduction in any medium, provided the original work is properly cited.

\begin{abstract}
Super-Critical water-cooled Fast Reactor (SCFR) is a feasible option for the Gen-IV SCWR designs, in which much less moderator and thus coolant are needed for transferring the fission heat from the core compared with the traditional LWRs. The fast spectrum of SCFR is useful for fuel breeding and thorium utilization, which is then beneficial for enhancing the sustainability of the nuclear fuel cycle. A SCFR core is constructed in this work, with the aim of simplifying the mechanical structure and keeping negative coolant void reactivity during the whole core life. A core burnup simulation scheme based on Monte Carlo lattice homogenization is adopted in this study, and the reactor physics analysis has been performed with DU-MOX and Th-MOX fuel. The main issues discussed include the fuel conversion ratio and the coolant void reactivity. The analysis shows that thorium-based fuel can provide inherent safety for SCFR without use of blanket, which is favorable for the mechanical design of SCFR.
\end{abstract}

\section{SCFR Conceptual Design}

In SCWR much less coolant water is needed for cooling the reactor, so a fast spectrum option (SCFR) is possible. With a harder spectrum, SCFR can have a higher conversion ratio. Thus, physically, SCFR is a kind of high conversion LWR design, for which the main approach to increase conversion ratio is to decrease the ratio of water to heavy metal, so as to decrease the moderation effect of water and make the spectrum hard [1-4].

The coolant void reactivity (CVR) is a crucial safety aspect of fast reactor design. Main concern arising from coolant voiding is the hardening of the neutron spectrum, which increases fast fission in both seed and blanket fuel regions and also increases neutron leakage at the same time. In order to decrease the CVR, the flat core design is usually adopted to increase the neutron leakage. But it is not an economical option for SCFR, since it is operated at a very high pressure and so a bigger and thicker pressure vessel is needed to contain the core. Thus, increasing neutron absorption at void condition is the key for achieving negative CVR in SCFR, and so blankets are very important since they are the only regions in the core where neutron capture strongly prevails over fission. A typical SCFR blanket design is shown in Figure 1, in which a $\mathrm{ZrH}$ layer is adopted to slow down the fast neutron leaked from seed assemblies at void condition and decrease the fast fission at blanket assemblies [5-8].

However, in SCFR the coolant in blanket assembly is very cold as very little heat generated, so the flow channels should be separated from those of the seed assemblies. This will make the flow path and the core mechanical design complicated. In order to simplify the mechanical design, we need to think out another way to keep CVR negative. Introducing thorium fuel is a possible option $[4,9-11]$, so this paper work mainly focuses on it.

A SCFR core conceptual design is proposed, as shown in Figure 2. No blanket assembly is adopted in the design. The core power density will increase in this case since a blanket assembly has much lower power than a seed assembly, and the mechanical design can be simplified as it is not needed to separate coolant flow in blanket and seed assemblies. In addition, it is possible to achieve negative CVR by changing the fuel design such as thorium fuel, which is a main purpose of this work.

The SCFR core can be divided into two radial regions, the inner core and the outer core. The numbers of assemblies for the two parts are generally the same. The inlet coolant flows downwards through outer core assemblies first. After mixing 


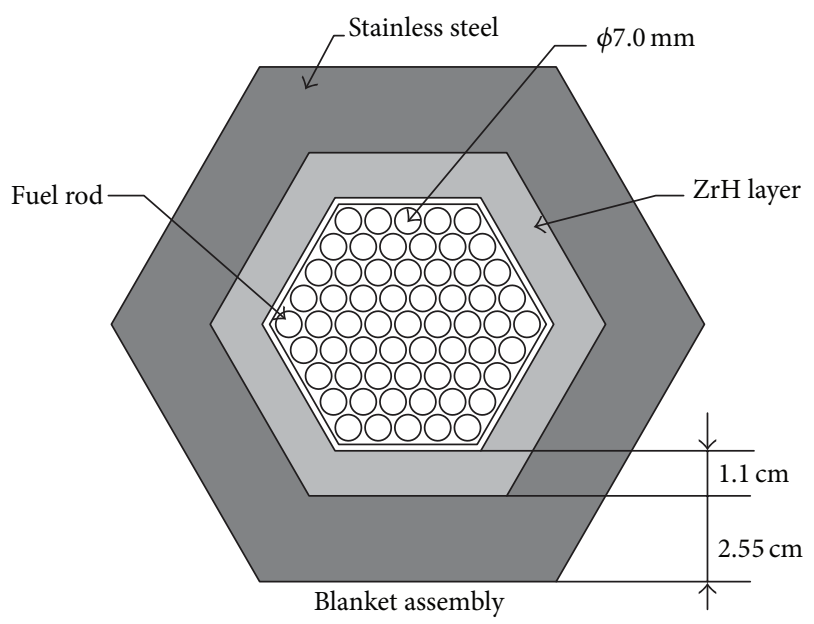

FIGURE 1: A typical SCFR blanket assembly design.

TABLE 1: SCFR core design parameters.

\begin{tabular}{lc}
\hline Parameters & Value \\
\hline Number of assembly & 241 (inner 121, outer 120) \\
Equivalent diameter/m & 2.97 \\
Active length/m & 3.6 \\
Thermal power/MWt & 3498 \\
Electric power/MWe & 1532 \\
Average linear heat generation & 16 \\
rate/kW/m & 140 \\
Average power density/MW/m $/ \mathrm{m}^{3}$ &
\end{tabular}

TABLE 2: SCFR assembly design parameters.

\begin{tabular}{lc}
\hline Parameters & Value \\
\hline Pellet OD/mm & 8.2 \\
Cladding OD/mm & 9.62 \\
Cladding thickness/mm & 0.63 \\
& MA956, Fe-21.5Cr-5.75Al- \\
Cladding material & $7.25 \mathrm{~g} / \mathrm{cm}^{3}$ \\
& 10.62 \\
Pitch/mm & 1.1 \\
P/D & 0.5 \\
Pin-to-channel-box gap/mm & 2.5 \\
Channel box thickness/mm & 1.0 \\
Gap between adjacent channel & 182.2 \\
box/mm & \\
Assembly width/mm &
\end{tabular}

in the lower plenum, the coolant flows upwards through the inner core assemblies to the upper plenum and then to the outlet. The main design parameters of SCFR core and assembly are listed in Tables 1 and 2.
TABLE 3: The different fuel forms chosen for study.

\begin{tabular}{llc}
\hline Fuel type & Fuel composition & Enrichment definition \\
\hline DU-MOX & $\mathrm{RGPuO}_{2}+\mathrm{DUO}_{2}$ & $\left({ }^{239} \mathrm{Pu}+{ }^{241} \mathrm{Pu}\right) / \mathrm{HM}$ \\
Th-MOX & $\mathrm{RGPuO}_{2}+\mathrm{ThO}_{2}$ & $\left({ }^{239} \mathrm{Pu}+{ }^{241} \mathrm{Pu}\right) / \mathrm{HM}$ \\
\hline
\end{tabular}

TABLE 4: SCFR core parameters with different fuel options.

\begin{tabular}{|c|c|c|}
\hline Parameters & Th-MOX & ThMOX + MOX \\
\hline \multicolumn{3}{|l|}{ Fuel forms } \\
\hline Inner & $(\mathrm{RGPu}+\mathrm{Th}) \mathrm{O}_{2}$ & $(\mathrm{RGPu}+\mathrm{Th}) \mathrm{O}_{2}$ \\
\hline Outer & $(\mathrm{RGPu}+\mathrm{Th}) \mathrm{O}_{2}$ & $(\mathrm{RGPu}+\mathrm{DU}) \mathrm{O}_{2}$ \\
\hline \multicolumn{3}{|l|}{ Enrichment/\% } \\
\hline Inner & 8.5 & 8.5 \\
\hline Outer & 7.5 & 6.0 \\
\hline \multicolumn{3}{|l|}{ Batch number } \\
\hline Inner & 3 & 3 \\
\hline Outer & 4 & 5 \\
\hline Core $k_{\text {eff }}$ (0 550 EFPDs) & $1.031 \sim 1.049$ & $1.030 \sim 1.050$ \\
\hline Maximum PPF & 1.48 & 1.98 \\
\hline \multicolumn{3}{|l|}{$\begin{array}{l}\text { Average discharge } \\
\text { burnup/MWd/kgHM }\end{array}$} \\
\hline Inner & 57.2 & 68.4 \\
\hline Outer & 71.0 & 64.5 \\
\hline Whole core & 62.9 & 67.0 \\
\hline \multicolumn{3}{|l|}{$\begin{array}{l}\text { Maximum discharge } \\
\text { burnup/MWd/kgHM }\end{array}$} \\
\hline Inner & 61.1 & 76.0 \\
\hline Outer & 74.2 & 71.8 \\
\hline \multicolumn{3}{|l|}{ FIR } \\
\hline Inner & 1.01 & 1.01 \\
\hline Outer & 0.81 & 1.01 \\
\hline Whole core & 0.93 & 1.01 \\
\hline
\end{tabular}

\section{The "Two-Step" MC Core Burnup Analysis Method}

Monte Carlo method has been widely used for the verification and validation of deterministic codes, and also for the analysis of many newly developed nuclear energy systems since it can deal with arbitrary geometry and spectrum configuration [12]. However, the efficiency of Monte Carlo calculation is too low for the ordinary large scale core designs, due to the long simulation time to get reliable results. With the rapid developing of computer technologies and parallel algorithms, the efficiency of Monte Carlo simulation has been greatly increased. Coupled neutronic thermal-hydraulic analysis of full core with Monte Carlo has been done [13], but core burnup analysis with continuous energy Monte Carlo is still difficult nowadays.

A "two-step" Monte Carlo core burnup analysis method is proposed in this work. Similar to the deterministic code systems, the core calculation scheme is divided into two steps. First, the assembly simulation is done with continuous energy 


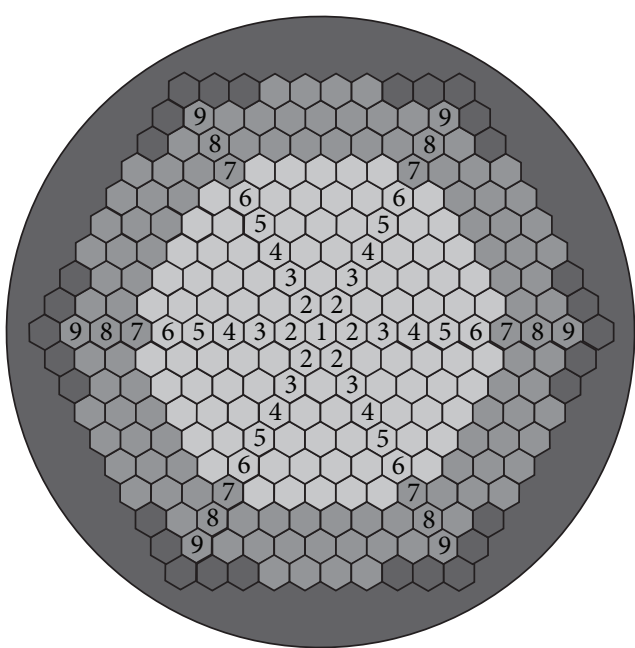

Assemblies with downward flow

Assemblies with upward flow

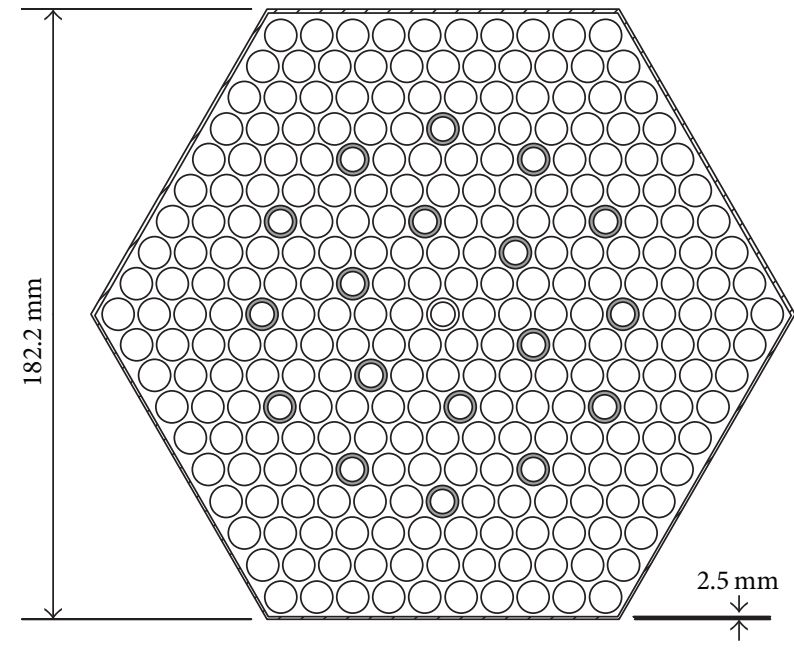

Figure 2: Conceptual design of SCFR core and assembly.

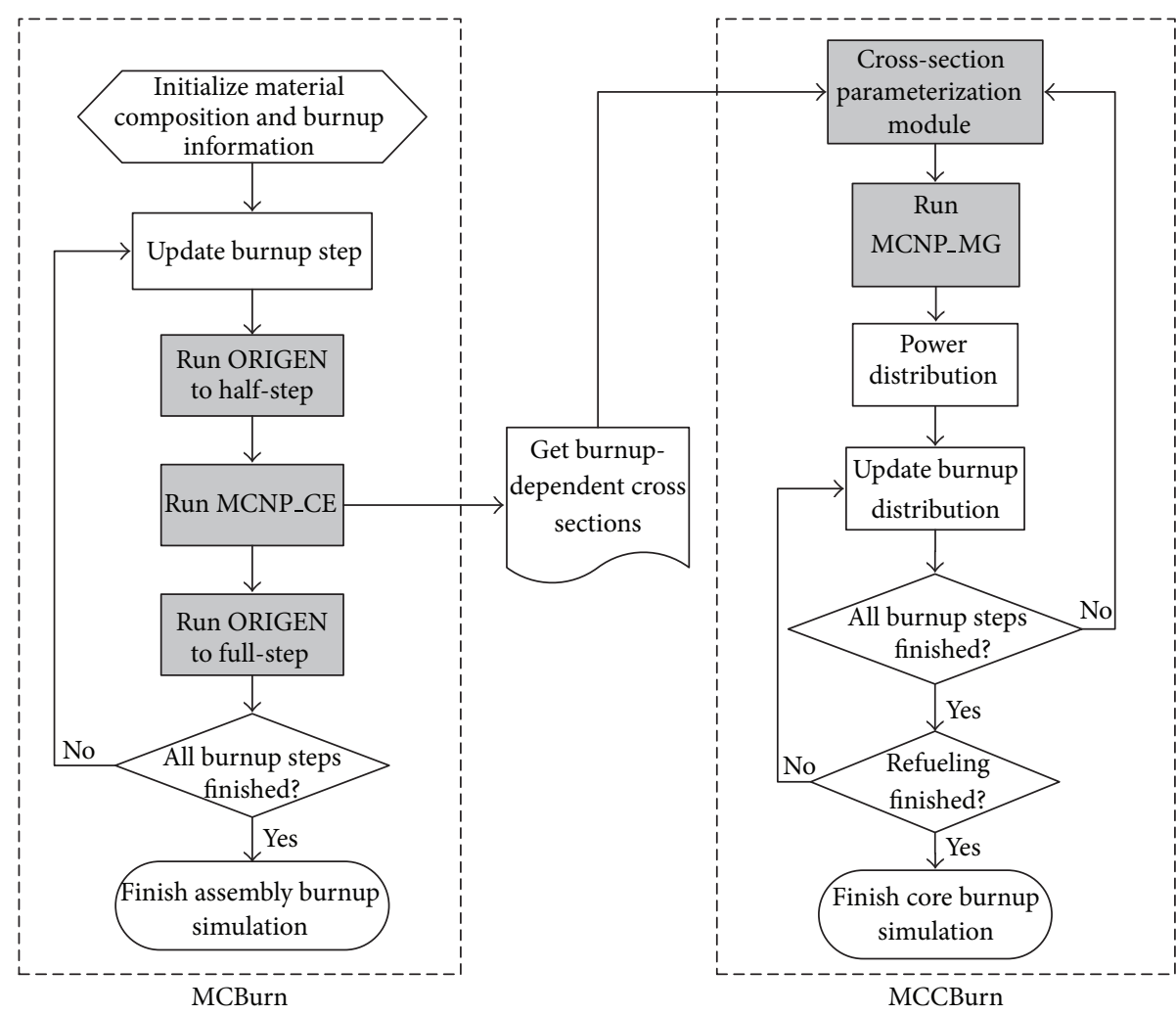

Figure 3: Two-step Monte Carlo core burnup analysis system.

Monte Carlo, and the assembly group cross-sections are tallied at the same time. Second, with these group constants, the core simulation is done with multigroup Monte Carlo [14], which can greatly increase the core simulation efficiency. The core burnup analysis can be done if the assembly group constants can be prepared for different burnup states.
The "two-step" core simulation scheme is illustrated in Figure 3. MCBurn, a coupling code of MCNP_CE (continuous energy mode of MCNP) and ORIGEN, is adopted for assembly burnup simulations [15]. The assembly group constants are gathered and organized to prepare group crosssections for core calculations. MCCBurn code is developed 

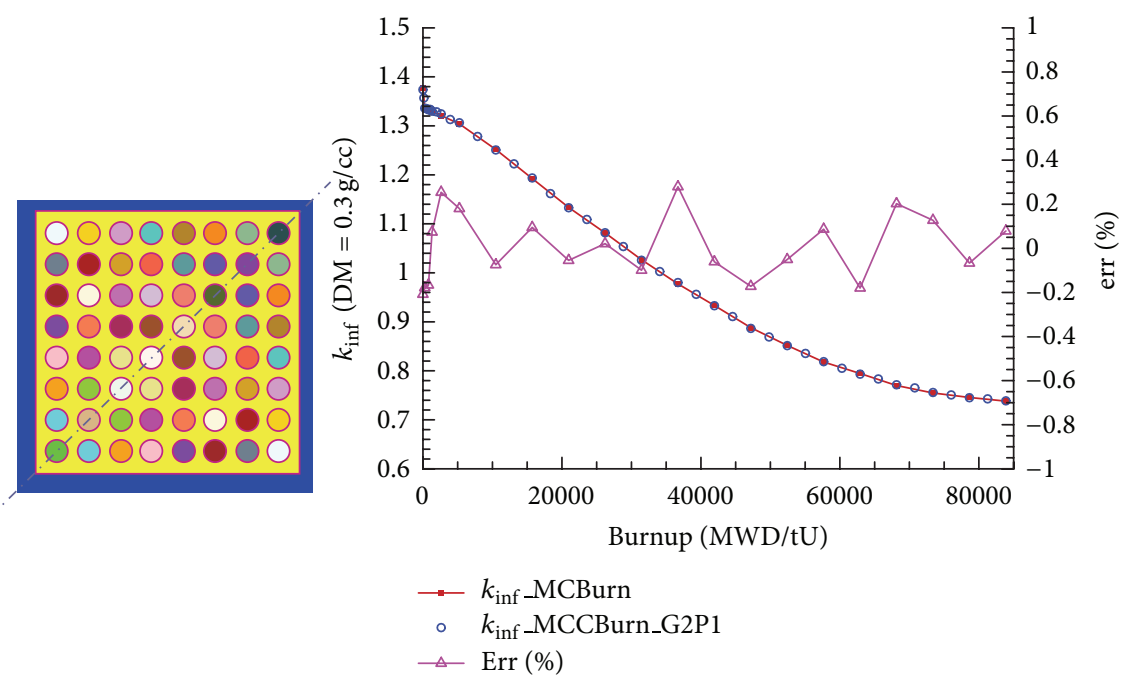

FIGURE 4: A BWR assembly model and its burnup calculation results.

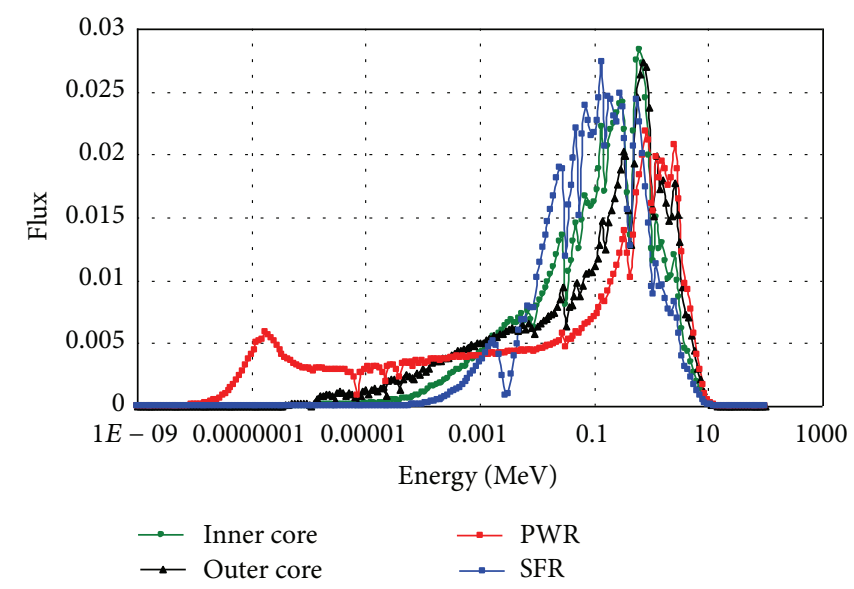

FIGURE 5: Spectrum comparison of SCFR (inner and outer core), PWR, and SFR.

to manage core burnup simulation, which uses MCNP_MG (multigroup mode of MCNP) to do core criticality simulations.

In order to justify the calculation tools, a BWR assembly with moderator density (DM) $0.3 \mathrm{~g} / \mathrm{cm}^{3}$ has been modeled using MCBurn and MCCBurn, with KCODE card of MCNP as "KCODE 50001.030 90." The burnup calculation results are shown in Figure 4. It can be seen that the differences of $k_{\text {inf }}$ between MCBurn and MCCBurn are well below $0.2 \%$, which reveals that the group cross-sections generated using our method is right.

\section{Reactor Physics Characteristics of SCFR with DU-MOX and Th-MOX}

In order to concentrate on the reactor physics characteristics analysis of SCFR, the thermal-hydraulic parameters have been simplified. The coolant densities of inner and outer core are set to be the average values along core height, $0.13 \mathrm{~g} / \mathrm{cm}^{3}$ and $0.6 \mathrm{~g} / \mathrm{cm}^{3}$, respectively. Besides, a pin cell is modeled to represent the assembly, which means the radial heterogeneity of assembly is ignored. This may introduce some errors to the results, but we think this can be neglected for the preliminary feasibility study.

We have chosen DU-MOX and Th-MOX for the comparing study, which are listed in Table 3 . The isotope weight vector of reactor grade plutonium $(\mathrm{RGPu})$ is as follows: $2.8 \%$ ${ }^{238} \mathrm{Pu}, 54.4 \%{ }^{239} \mathrm{Pu}, 22.8 \%{ }^{240} \mathrm{Pu}, 11.8 \%{ }^{241} \mathrm{Pu}, 7 \%{ }^{242} \mathrm{Pu}$, and $1.2 \%{ }^{241} \mathrm{Am}$. The depleted uranium (DU) is assumed to have 0.25 weight $\%{ }^{235} \mathrm{U}$.

3.1. Spectrum Comparison. Supposing the fuel is DU-MOX with an enrichment of $7.5 \%$, the inner and outer core spectrums are shown in Figure 5. The spectrums of PWR and sodium-cooled Fast Reactor (SFR) are also included for comparison. It can be seen that there is no PWR-like thermal peak for SCFR's spectrum. Spectrum of inner core is harder than outer core since the coolant density is lower. 

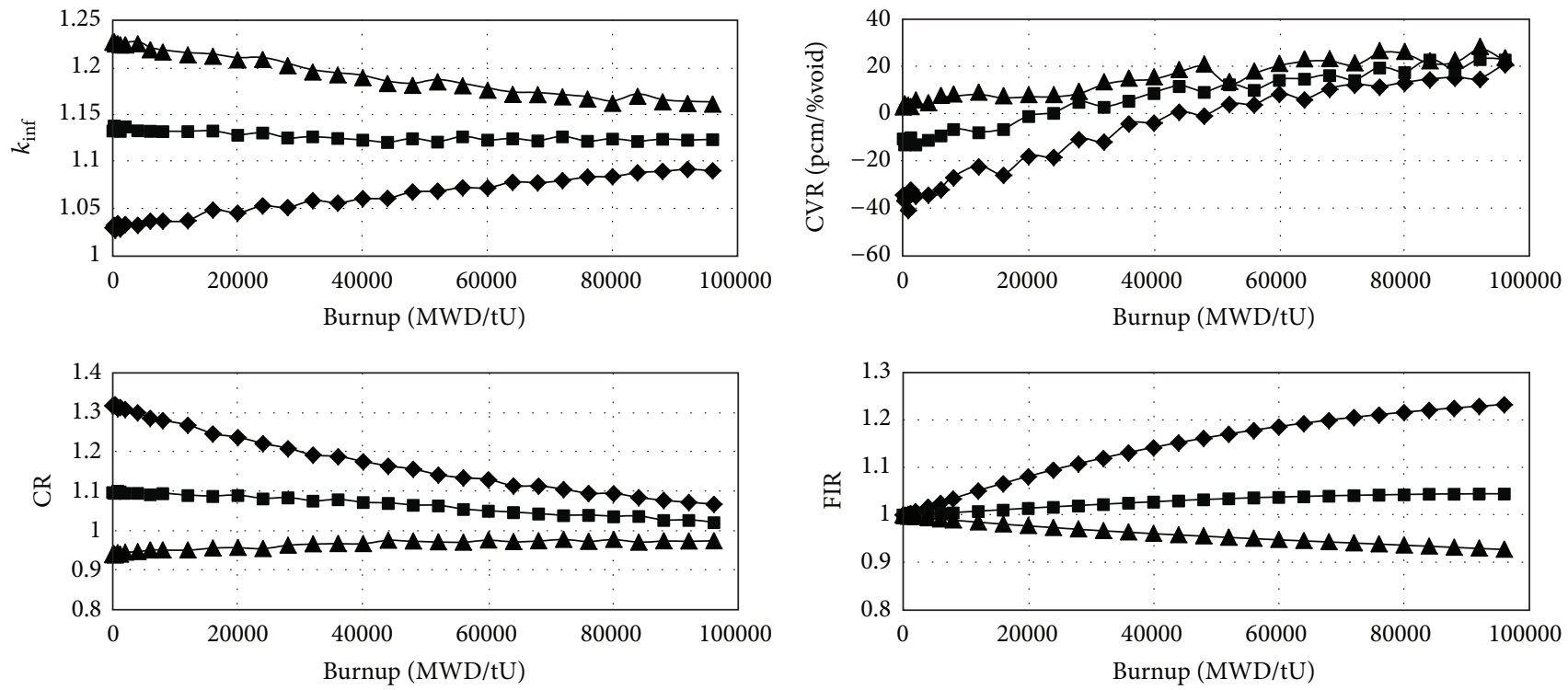

- fis_Pu $=6 \%$

- fis_Pu $=7.5 \%$

- fis_Pu $=9 \%$

FIGURE 6: Inner cell burnup performances with DU-MOX fuel.
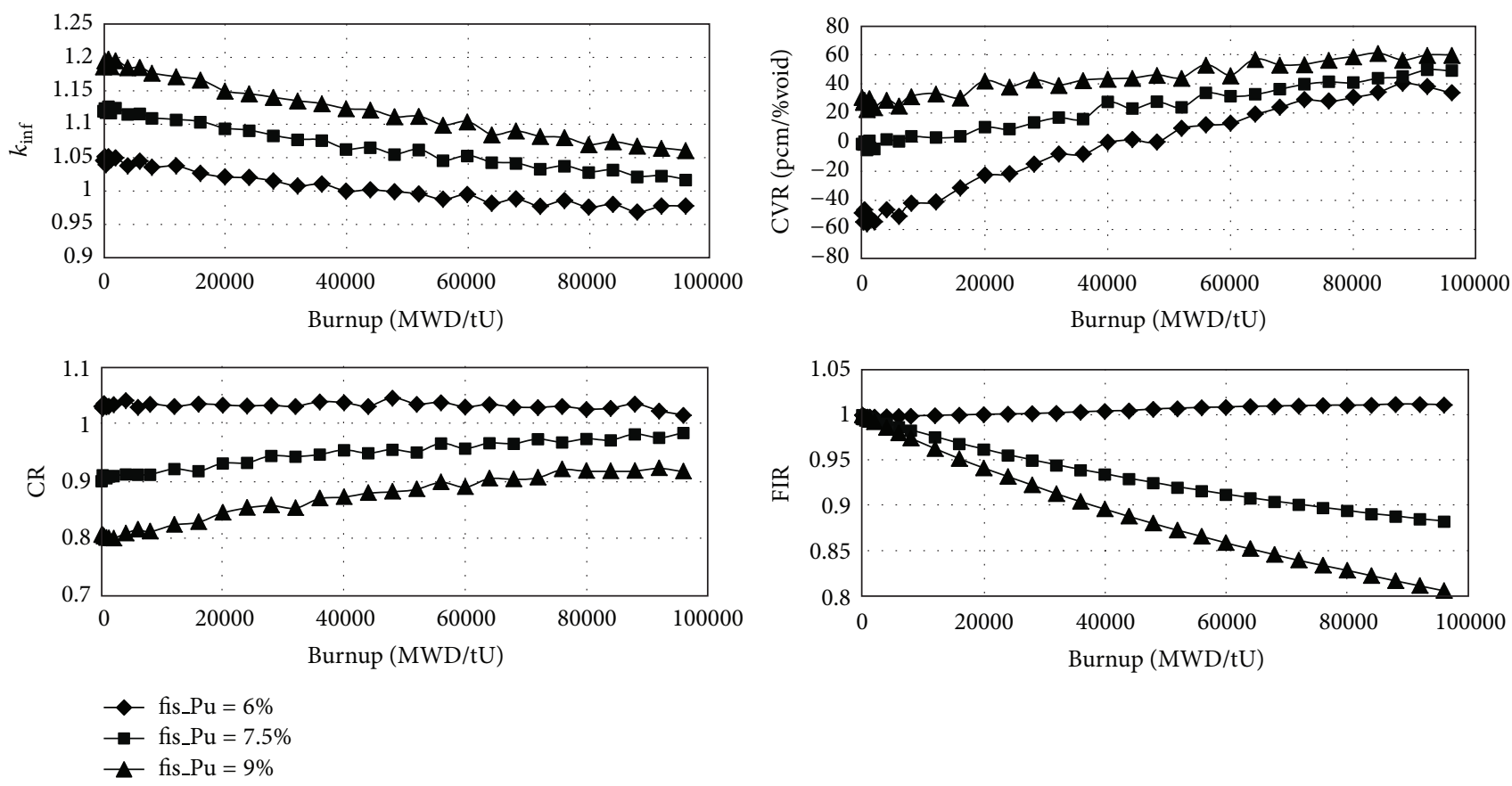

FIGURE 7: Outer cell burnup performances with DU-MOX fuel.

\subsection{Cell Burnup Performance}

3.2.1. DU-MOX Fuel Cell. The main burnup performances of inner and outer cells with different enrichments are shown in Figures 6 and 7. Where CVR is the coolant void reactivity; $\mathrm{CR}$, conversion ratio, is defined as the ratio of capture rate of fertile nuclides $\left({ }^{232} \mathrm{Th},{ }^{238} \mathrm{U},{ }^{238} \mathrm{Pu}\right.$, and $\left.{ }^{240} \mathrm{Pu}\right)$ to absorption rate of fissile nuclides $\left({ }^{233} \mathrm{U},{ }^{235} \mathrm{U},{ }^{239} \mathrm{Pu}\right.$, and $\left.{ }^{241} \mathrm{Pu}\right)$; and FIR, fissile inventory ratio, is defined as the ratio of total amount of fissile material to the initial loading fissile material.

From these figures we can see that the cell burnup performances are sensitive to fuel enrichment. With the increasing of fuel enrichment: cell initial $k_{\text {inf }}$ increases notably, and the differences decrease with burnup; CVR goes positive rapidly, 

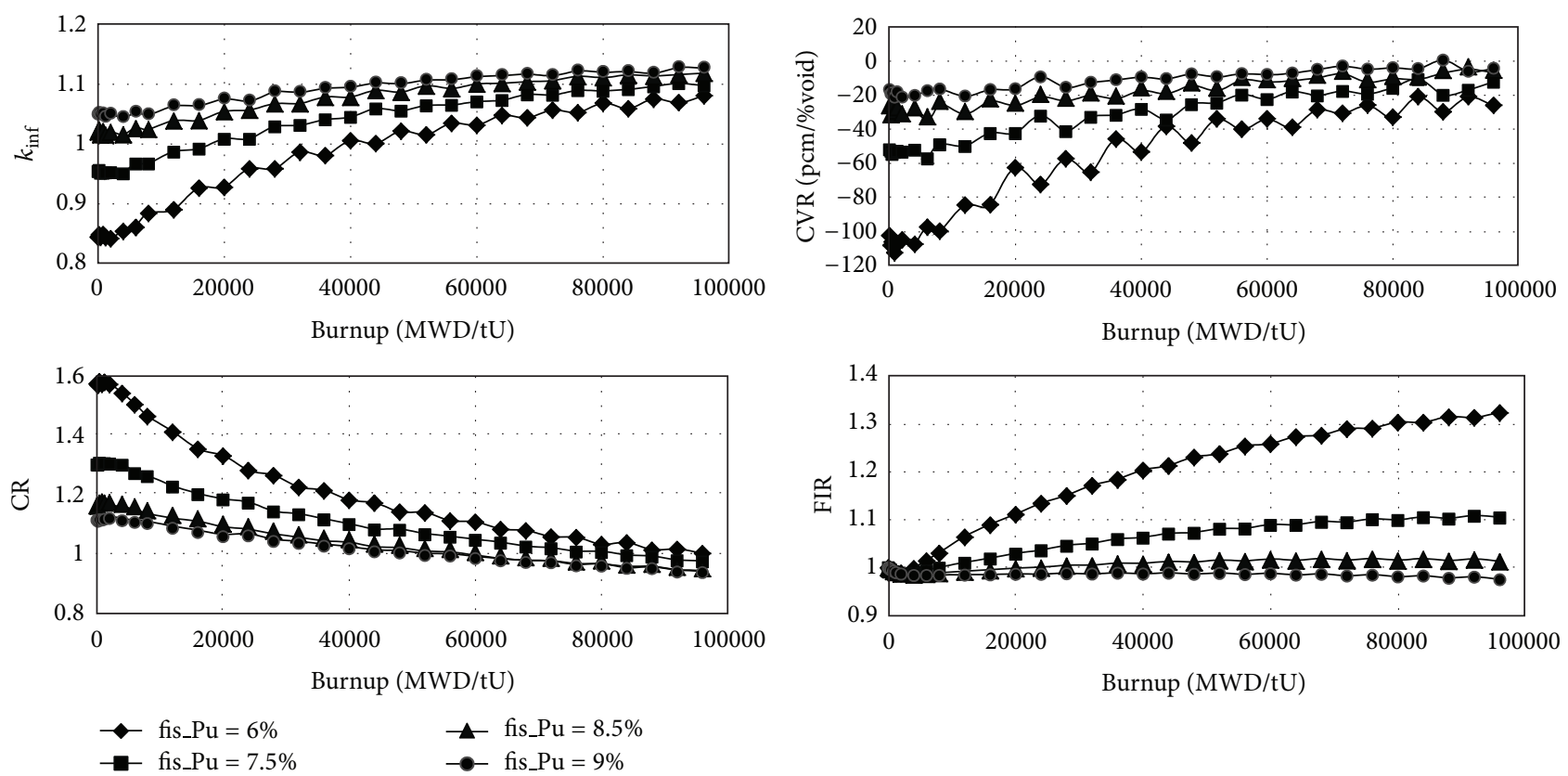

FIGURE 8: Inner cell burnup performances with Th-MOX fuel.
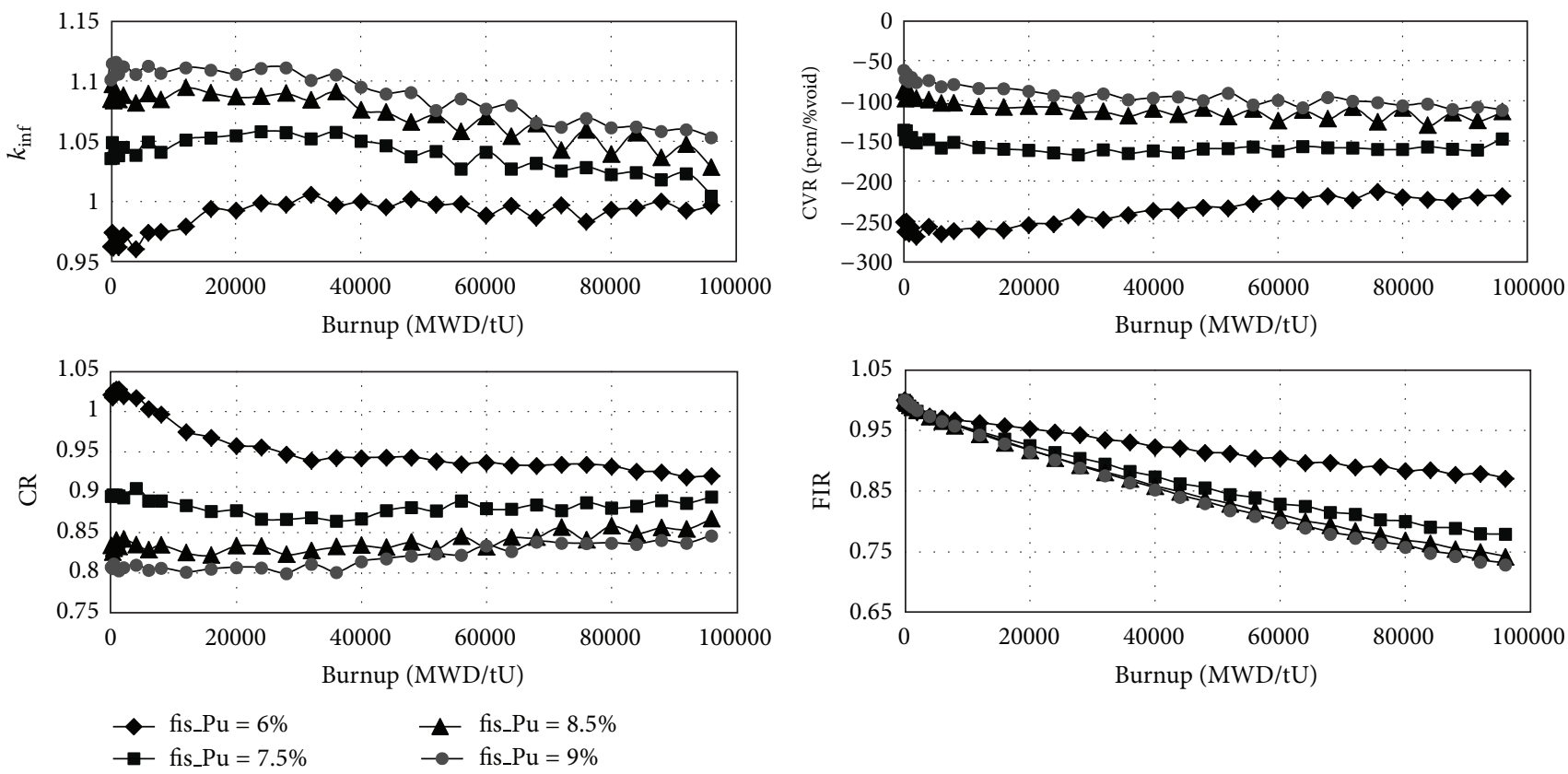

FIGURE 9: Outer cell burnup performances with Th-MOX fuel.

and it increases slowly with burnup; CR and FIR decreases significantly.

3.2.2. Th-MOX Fuel Cell. The Th-MOX fuel cell burnup performances for inner and outer core are shown in Figures 8 and 9. The same trends can be observed for the parameters when fuel enrichment and burnup changed. A great advantage of adopting thorium fuel is that the CVR of cell can be kept negative for a wide range of enrichment and for the whole life cycle. Considering the negative effect of neutron leakage, the CVR of SCFR core will be negative. So in the following core analyses, CVR is not discussed in detail.

Thus, thorium fuel is very suitable for SCFR, and ThMOX is adopted in the following study. Considering the critical ability, the fuel enrichment for inner and outer core is chosen as $8.5 \%$ and $7.5 \%$, respectively. 


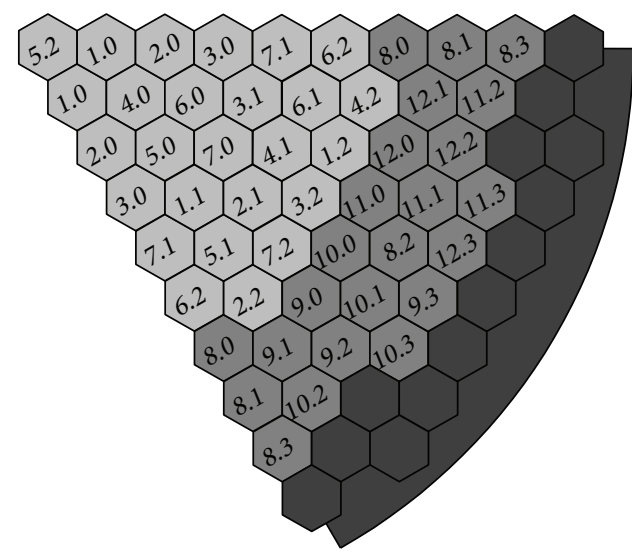

(a) Inner: 3-batch; outer: 4-batch

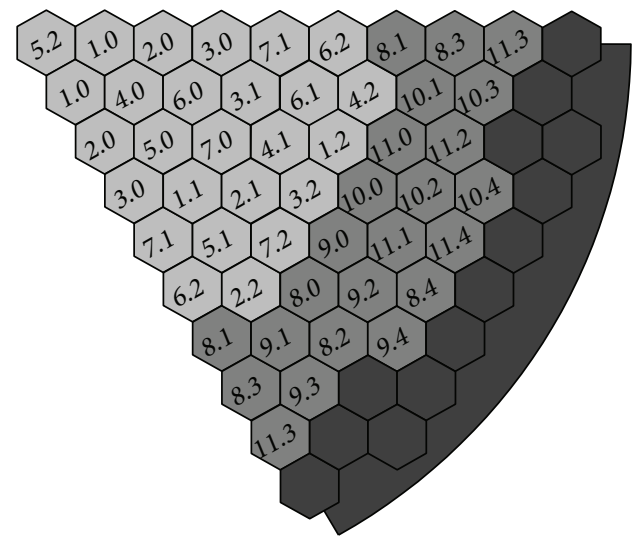

(b) Inner: 3-batch; outer: 5-batch

FIGURE 10: Core loading scheme (m.n: $\mathrm{m}$-the assembly group number; $\mathrm{n}$-cycles of the assembly has been burned).

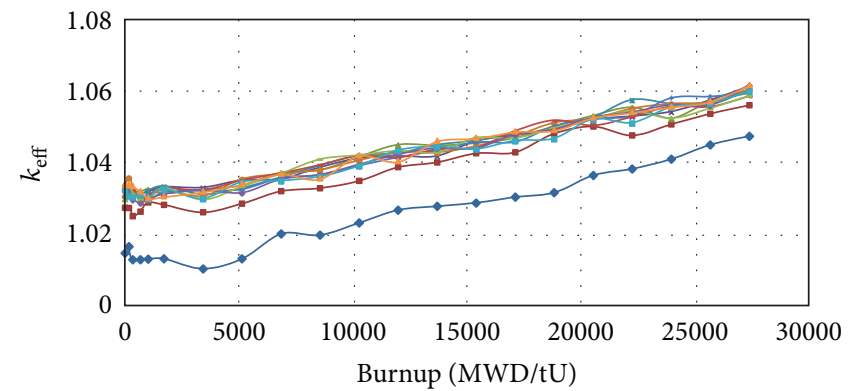

$$
\begin{aligned}
& \rightarrow k_{\text {eff }} \mathrm{C} 1 \\
& -k_{\text {eff-C2 }} \\
& \rightarrow k_{\text {eff }-\mathrm{C} 3} \\
& \rightarrow k_{\text {eff }-\mathrm{C} 4} \\
& * k_{\text {eff }-\mathrm{C} 5} \\
& -k_{\text {eff_C6 }} \\
& -k_{\text {eff }-\mathrm{C} 7} \\
& -k_{\text {eff }-\mathrm{C} 8} \\
& \text { - } k_{\text {eff_-C9 }} \\
& \rightarrow k_{\text {eff }-\mathrm{C} 10} \\
& \because k_{\text {eff }-\mathrm{C} 11} \\
& \leadsto k_{\text {eff }-}-\mathrm{C} 12
\end{aligned}
$$

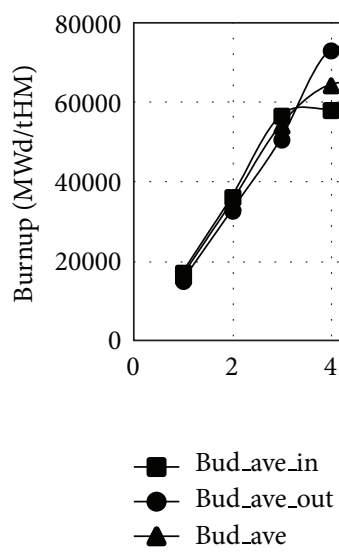

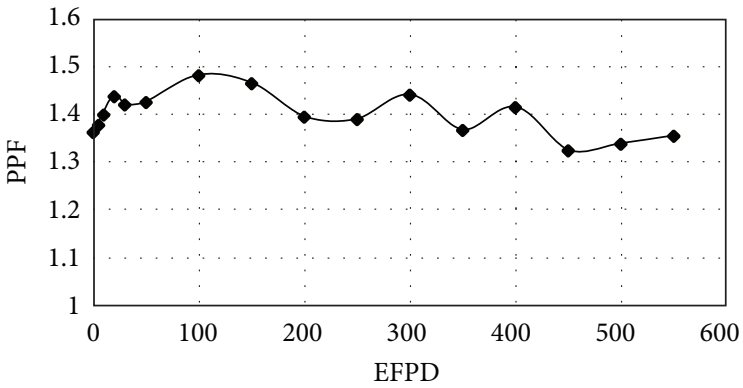

- C7 C12 average

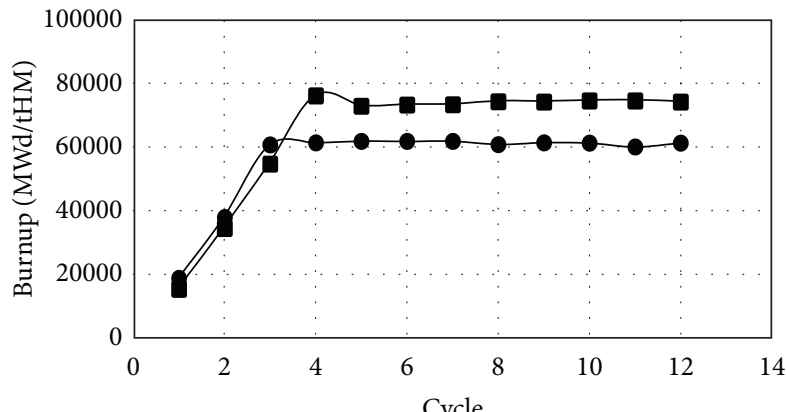

- Bud_max_out Bud_max_in

FIGURE 11: Multicycle burnup simulation results for Th-MOX core.

\subsection{Core Burnup Performance}

3.3.1. Core Loading Pattern. In order to get the equivalent fuel cycle performances, we need to design the fuel loading patterns. The inner and outer core are considered independently, since they have different reactor physics characteristics.
Assuming that the average linear heat generation rate is $16 \mathrm{~kW} / \mathrm{m}$, the specific power density should be about $34 \mathrm{~kW} / \mathrm{kgHM}$. The object burnup is supposed to be $60 \sim$ $70 \mathrm{MWd} / \mathrm{kgHM}$, so an assembly should stay in core for $1800 \sim$ 2000 days, and loading pattern can be 3-, 4-, or 5-batch loading pattern. In this work, the cycle length is fixed as 550 

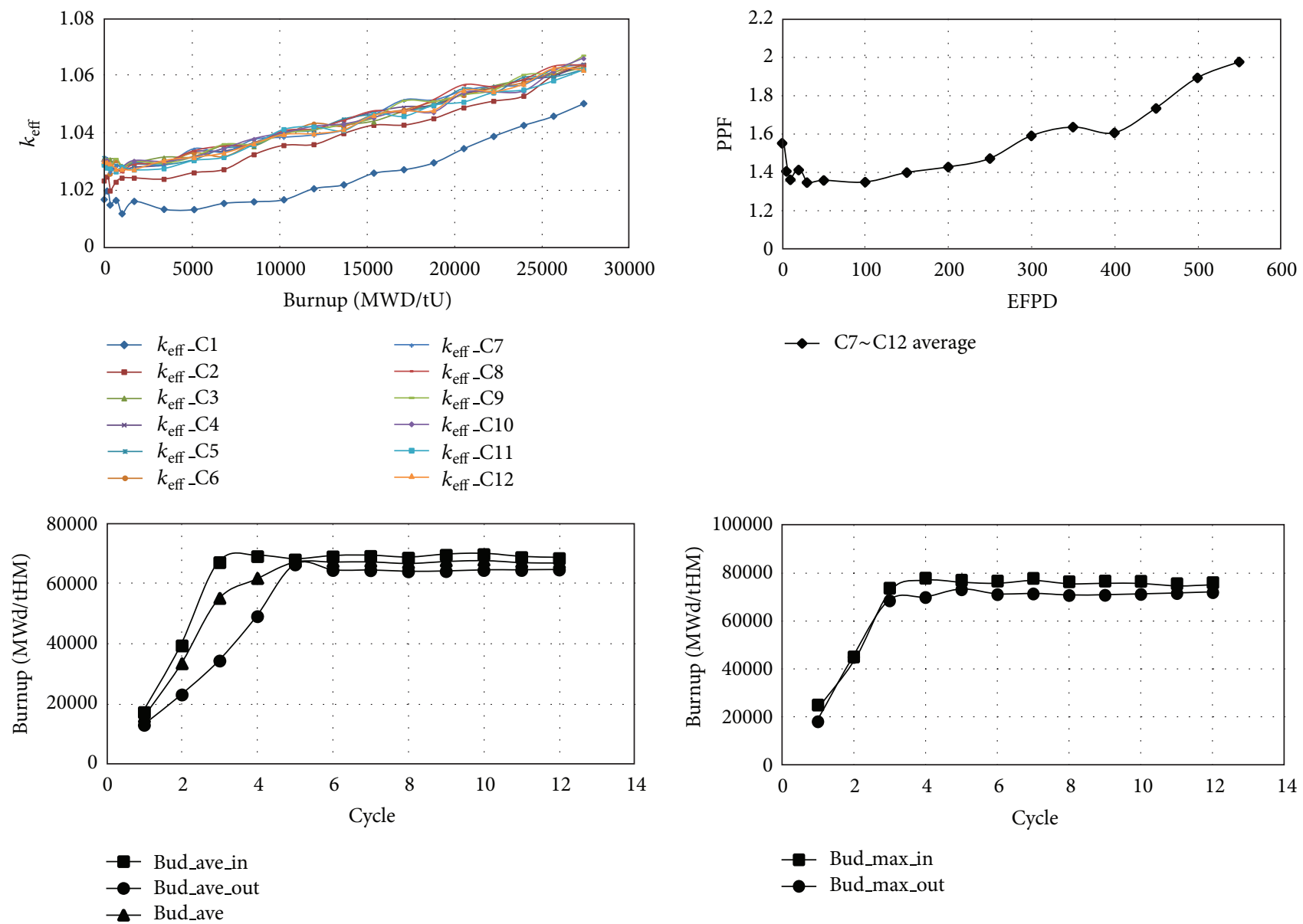

FIGURE 12: Multicycle burnup simulation results for Th-MOX+DU-MOX core.

days. Considering the higher power density of inner core, 3batch loading pattern is suitable for inner core, while 4- or 5 -batch loading pattern for outer core. The loading schemes for 1/6 symmetric core are shown in Figure 10.

3.3.2. Multicycle Simulation. The multicycle core simulation results are shown in Figure 11. The in-3-out-4 batch loading pattern is adopted. PPF (peak power factor) is the ratio of the maximum assembly power to the average assembly power. The $k_{\text {eff }}$ of core increases slowly with burnup. The average and maximum discharge burnups of inner core $(57 \mathrm{MWd} / \mathrm{kgHM}$ and $61 \mathrm{MWd} / \mathrm{kgHM}$ ) are lower than that of the outer core (71 MWd·kgHM and $74 \mathrm{MWd} / \mathrm{kgHM}$ ).

Since the inner and outer core regions are not coupled tightly, the fuel forms can be different for the two regions. Considering the CVR, DU-MOX should not be loaded in the inner region, since the cell burnup results indicate that local CVR may be positive at a burnup higher than $40 \mathrm{GWd} / \mathrm{tHM}$. Considering that many neutrons may leak from the core at void condition, it is possible to load DUMOX fuel in the outer region while still keeping a negative CVR for the whole core. Th-MOX fuel is loaded in the inner region. The enrichments for Th-MOX and DU-MOX are $8.5 \%$ and 6\%. In-3-out-5 batch loading pattern is adopted, and the multicycle core simulation results are shown in Figure 12. The difference of discharge burnups between inner and outer core region is decreased. The main core parameters at equivalent cycle are listed in Table 4.

\section{Conclusion}

In this work, a SCFR core conceptual design is proposed. The core can be divided into two radial regions, the inner region and the outer region. The spectrums of the two regions are different, which results in their different reactor physics characteristics. The fuel forms and the loading patterns of the two regions can be designed independently. Unlike the significant $k_{\text {eff }}$ decrease in the traditional LWRs, the $k_{\text {eff }}$ of the proposed SCFR core increases slowly during the whole life cycle. This reveals that SCFR has good fuel conversion ability. With the adoption of thorium fuel, the CVR can be kept negative during the whole life cycle without use of blanket, which is also beneficial for increasing the power density and simplifying the mechanical design. 


\section{Conflict of Interests}

The authors declare that there is no conflict of interests regarding the publication of this paper.

\section{Acknowledgments}

This work was sponsored by the National Basic Research Program of China (2007CB209800) and the National Natural Science Foundation of China (Approved no. 11305036).

\section{References}

[1] Y. Oka, T. Jevremovic, and S. Koshizuka, "A direct-cycle, supercritical-water-cooled fast breeder reactor," Journal of Nuclear Science and Technology, vol. 31, no. 1, pp. 83-85, 1994.

[2] Y. Ishiwatari, Y. Oka, and S. Koshizuka, "Breeding ratio analysis of a fast reactor cooled by supercritical light water," Journal of Nuclear Science and Technology, vol. 38, no. 9, pp. 703-710, 2001.

[3] S. Uchikawa, T. Okubo, T. Kugo et al., "Conceptual design of innovative water reactor for Flexible Fuel Cycle (FLWR) and its recycle characteristics," Journal of Nuclear Science and Technology, vol. 44, no. 3, pp. 277-284, 2007.

[4] Z. Peng, Research on the reactor physics analysis methods and characteristics of supercritical water-cooled reactor [Ph.D. thesis], Tsinghua University, 2012, (Chinese).

[5] Y. Oka and T. Jevremovic, "Negative coolant void reactivity in large fast breeder reactors with hydrogenous moderator layer," Annals of Nuclear Energy, vol. 23, no. 14, pp. 1105-1115, 1996.

[6] J. Yo, Y. Ishiwatari, Y. Oka et al., "Composite core design of high power density supercritical water cooled fast reactor," Proceedings of the GLOBAL, Tsukuba, Japan, 2005.

[7] L. Cao, Y. Oka, Y. Ishiwatari, and Z. Shang, "Fuel, core design and subchannel analysis of a superfast reactor," Journal of Nuclear Science and Technology, vol. 45, no. 2, pp. 138-148, 2008.

[8] L. Cao, Y. Oka, Y. Ishiwatari, and S. Ikejiri, “Three-dimensional core analysis on a super fast reactor with negative local void reactivity," Nuclear Engineering and Design, vol. 239, no. 2, pp. 408-417, 2009.

[9] International Atomic Energy Agency, "Thorium fuel cyclepotential benefits and challenges," Tech. Rep. IAEA-TECDOC1450, 2005.

[10] S. Permana, N. Takaki, and H. Sekimoto, "Breeding and void reactivity analysis on heavy metal closed-cycle water cooled thorium reactor," Annals of Nuclear Energy, vol. 38, no. 2-3, pp. 337-347, 2011.

[11] V. Jagannathan and U. Pal, "Towards an intrinsically safe and economic thorium breeder reactor," Energy Conversion and Management, vol. 47, no. 17, pp. 2781-2793, 2006.

[12] X-5 Monte Carlo Team, "MCNP—a general Monte Carlo Nparticle transport code, version 5," Tech. Rep. LA-CP-03-0284, Los Alamos National Laboratory, 2003.

[13] D. Kotlyar, Y. Shaposhnik, E. Fridman, and E. Shwageraus, "Coupled neutronic thermo-hydraulic analysis of full PWR core with Monte-Carlo based BGCore system," Nuclear Engineering and Design, vol. 241, no. 9, pp. 3777-3786, 2011.

[14] J. C. Wagner, E. L. Redmond, S. P. Palmtag, and J. S. Hendricks, "MCNP: multigroup/adjoint capabilities," Tech. Rep. LA-12704, Los Alamos National Laboratory, 1994.
[15] Y. Ganglin, W. Kan, and W. Yuhong, "MCBurn—a coupling package of program MCNP and ORIGEN," Atomic Energy Science and Technology, vol. 37, no. 3, pp. 250-254, 2003. 


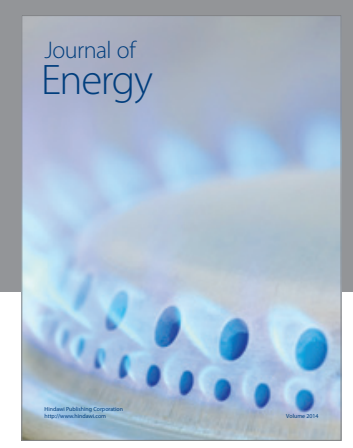

Journal of

Industrial Engineering
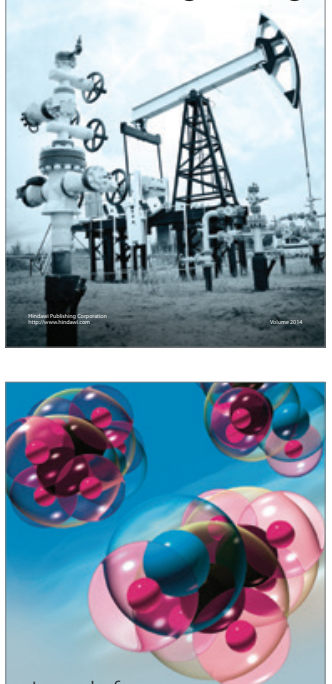

Fuels
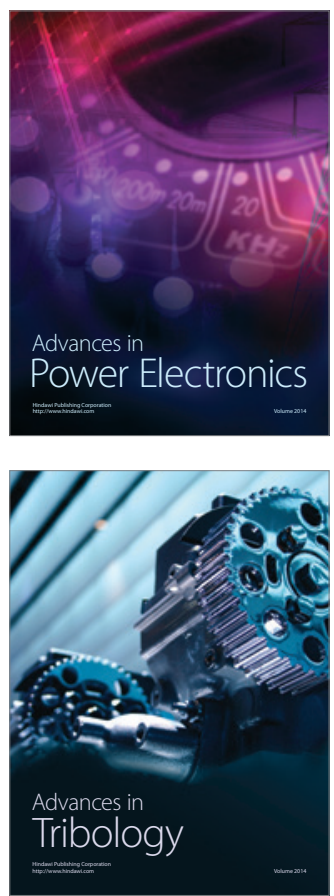

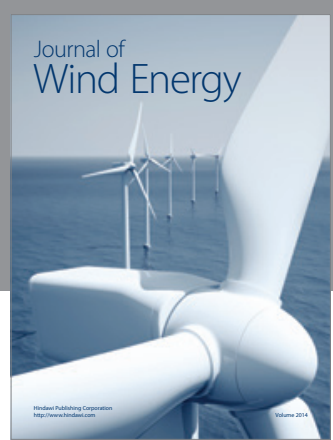

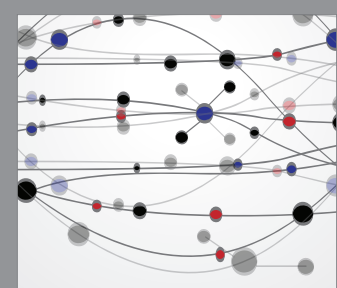

The Scientific World Journal

Submit your manuscripts at http://www.hindawi.com

Journal of

Structures
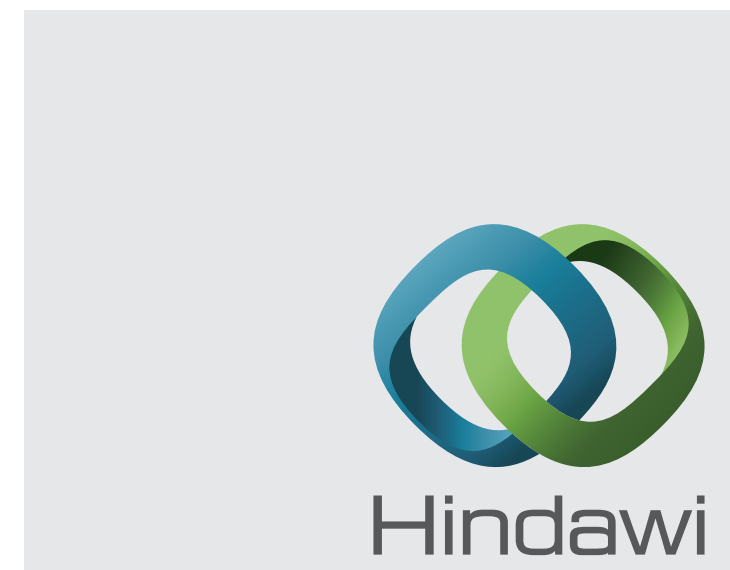

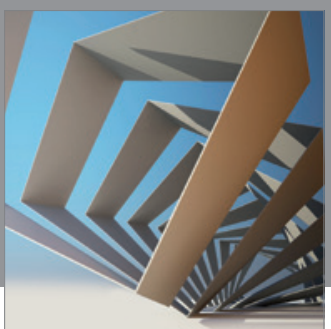

Rotating

Machinery
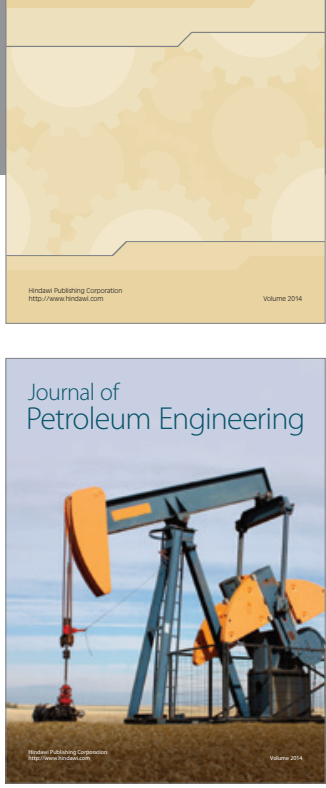

Journal of

Solar Energy
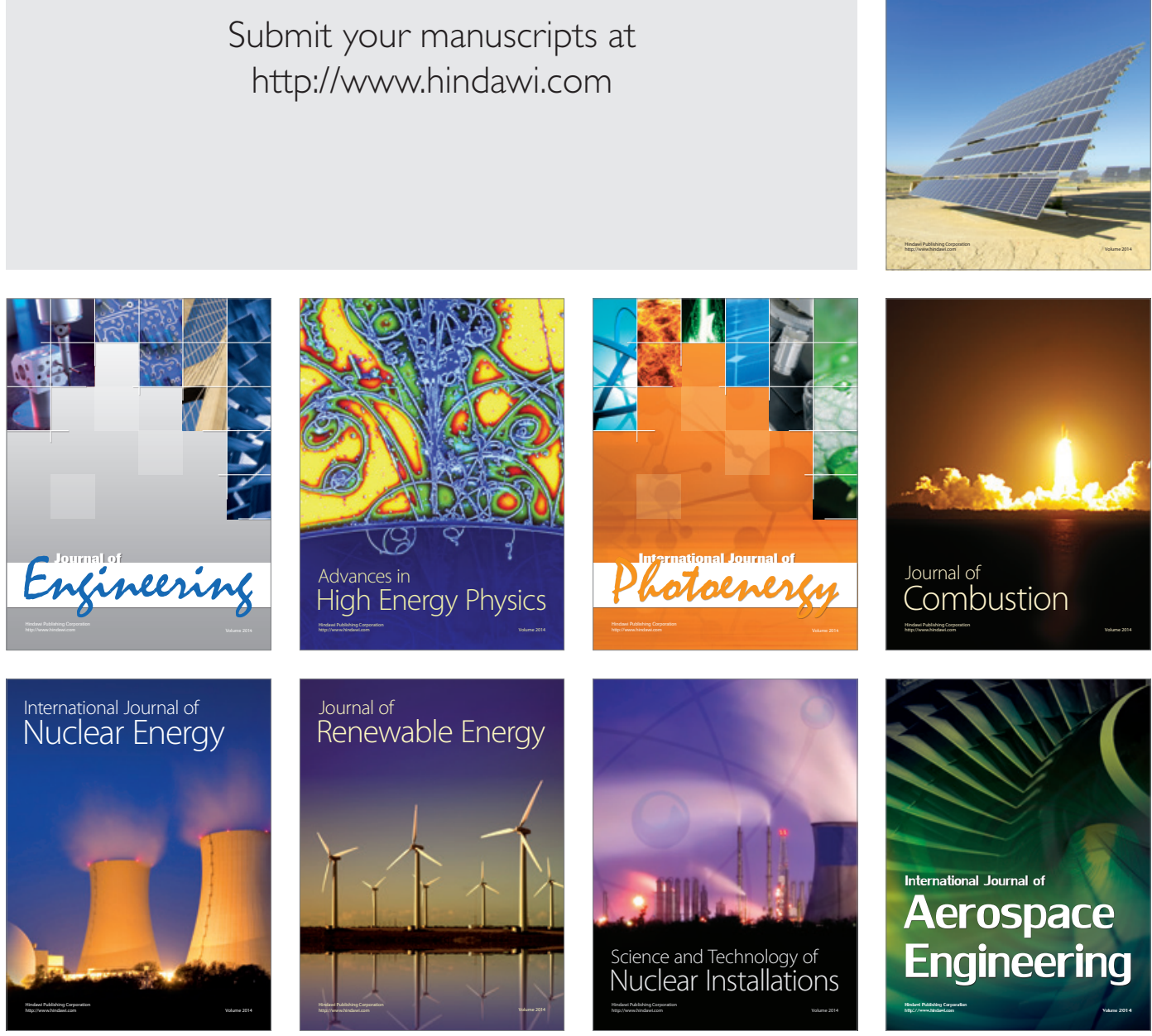